\title{
Commentary: Ethnocentric Considerations in the Allocation of Vaccines in Africa
}

\author{
Ishmael D. Norman
}

\section{ABSTRACT}

\begin{abstract}
This paper suggests that, just as the world community is concerned with 'vaccine nationalism' in the acquisition and distribution of vaccines, it should also be concerned with 'vaccine tribalism' in the respective African nations. This call is made because, African nations do not have impressive records of ethical distribution and apportionment of scarce resources, be it the delivery of healthcare services, medical doctors, or the national wealth, jobs, and the siting of national projects. Ethnocentric considerations, cronyism, big-man-ism, power, often trump ethical values of beneficence, non-malfeasance, equity, and fairness.
\end{abstract}

Keywords: Africa; Ethical Vaccine Distribution; Vaccine Nationalism; Vaccine Tribalism.

\section{INTRODUCTION}

What kind of a model would African nations use in the distribution of vaccines within their respective nations that is governed by ethical principles like beneficence, nonmalfeasance, due process, equity, justice as fairness in the allocation of the wealth of the nation, and virtue? These principles are not strongly associated with public conduct, healthcare delivery system; and, in the sharing of the national cake. The distribution of life-saving vaccines against the COVID-19 virus would, more likely than not, face the same inequitable, in-egalitarian and unfair apportionment and allocative culture, that has been the basis of wealth and health distribution in many African nations for a long time [1]. What model would be used for the distribution of the coronavirus vaccine by the usually partisan, ethnic identity driven governance system, is germane in view of vaccine nationalism on the world stage [2], [3]. This is because, ethical and moral issues have arisen even on the world stage, as the available vaccines output by the handful of companies manufacturing vaccines have been monopolized by wealthy nations with better organized health systems [4], [5]. Vaccine Nationalism is at the expense of the already corruption ridden and poorly resourced healthcare delivery system in many, if not most, nations in Africa, and other poor nations of the world. This anomaly has led to the concept of vaccine nationalism practiced by the wealthy nations, even as vaccination efforts are under way in those wealthy nations [1], [5]. In order to correct the skewed vaccine distribution system that has emerged in favor of better planned and wealthy nations, the World Health Organization, Gavi and the Coalition for Epidemic Preparedness Innovations (CEPI) and vaccine producers with the European Union, proposed the COVAX facility for the fair distribution of vaccines [4], [5].

\author{
Submitted : February 10, 2021 \\ Published : March 31, 2021 \\ ISSN: $2593-8339$ \\ DOI: $10.24018 /$ ejmed.2021.3.2.714 \\ Ishmael D. Norman \\ $\mathrm{Ph}$. D., J. D., President, Institute for \\ Security, Disaster and Emergency \\ Studies, Sandpiper Place, Ghana. \\ (e-mail: ishmael_norman@yahoo.com \\ ishmael.norman@isdesghana.org) \\ *Corresponding Author
}

COVAX supply chain mechanism is akin to the operations of a bulk purchasing entity. COVAX, which invariably is funded by some of the same wealthy nations accused of practicing vaccine nationalism either directly or through their financial support of the WHO and other Civil Society Organizations in COVAX as well as huge funding to some of the vaccine developers, is motivated by ethical principles of fairness and equality. Perhaps, its activities fall within the zone of supererogation rather than a fixed obligation to provide such services to the otherwise, poorly managed economies by choice and perhaps, ignorance [4], [6].

\section{URGENCY FOR VACCINES}

The urgency of this initiative is necessitated by the reality that, according to CDC Africa, Africa's COVID-19 statistics were over 3 million cases and over 87,000 deaths as of $29 / 1 / 2021$. These numbers continue to go up daily due to a number of factors, including the poor adherence to COVID19 protocols of mask wearing, hand-washing and social distancing as well as the emergence of a variant of COVID19 virus, dubbed as the UK or South African virus. At the same time, Ghana had recorded over 70,000 confirmed cases, with 449 deaths and 791 daily new cases. The active cases were 6,095, which has grown from less than a one thousand in the middle of January to this figure. Against the resurgence of new cases and a new strain of the COVID-19 virus that is reported to be more virulent and easy infectivity, there seems to be official inertia in accessing or purchasing some of the available vaccines for the nation on the international market. The successful rollout of a national COVID-19 vaccination program depends on the nation's purchasing power and acquisition of vaccines/supplies. Against such internal developments in the case of Ghana, is the real public health 
concern of vaccine nationalism.

The WHO plan of intervention for the coronavirus vaccines is to treat 20 percent of each country's population in Africa by the end of 2021. That is to say, the "supply of 600 million doses of vaccine by end 2021. Among the WHO's stated approaches for the distribution of vaccines to achieve the 20 percent vaccine penetration is first, "priority is given to countries where outbreaks are most serious" [5], [6].

If African nations go by this method, the urban and periurban centers of the respective nations, often the epicenters of coronavirus cases, would benefit more than those in the rural and distant settlements. Another approach is the suggestion by WHO that, "the allocation of vaccines should be determined by the number of medical workers or elderly population in a country" [7]. This approach too, would advantage the urban centers disproportionately against the health interests of those in rural areas. Even within the same cities, the richer neighborhoods, would have uneven advantage over the working-class to poor suburbs. This researcher has not found any African national articulation of vaccine distribution approach to be used in the mass vaccination program, whenever the COVAX vaccines become available to the respective nations. Although Morocco, Egypt, Seychelles, South Africa, and Guinea have already begun vaccinations. South Africa has, however, halted the rollout of the AstraZeneca COVID-19 vaccine, due to efficacy concerns against the South African COVID-19 strain. "So far, six African countries have confirmed cases of this variant, including Botswana, Ghana, Kenya, Mayotte, Zambia" [8]. It is also estimated that "Africa will need 1.5 billion vaccine doses to immunize 60 percent of its population, costing between $\$ 7$ and $\$ 10$ billion USD" [5], [6], [8].

Clearly this is a huge expenditure which the perennially and centrally mal-administered economies of Africa do not have. Certainly, wherever there is scarcity of resources to be allocated in a given ecosystem, conflicts arise due to perceived inequities and outright discrimination on national, ethnic and identity lines. Africa has an unimpressive historical record of discriminatory allocative practices in most resources, be it health, education, wealth, housing, employment and security protections, that there is a high probability that, the allocation of vaccines internally, without a well-thought-out plan, would lead to disastrous consequences and in-fighting. The author, therefore, suggests the Fair Priority Model pushed by Emanuel et al. and others [1], [5]. The theoretical basis for the Fair Priority Model on vaccine distribution and allocation on the global scale, relies on equity and fairness as justice in the allocation and distribution of vaccines. It uses epidemiologic and other tools such as Standard Expected Years of Life Lost (SEYLL), SEYLL as a health metric to measure mortality and morbidity. SEYLL is part of Disability Adjusted Life Year (DALY) as a measure of disease burden. Emanuel et al. [5] suggested this approach against the WHO "Priority approach dictated by the severity of infections".

They also suggested economic metric to measure the extent to which people would be spared from poverty. The economic impact of COVID-19 even in wealthy nations have been very biting, let alone in those already self-immolated and deprived nations such as Ghana, Nigeria and other where about 60 percent of the population live on less than \$1USD a day. Emanuel et al., also suggested population metric based on prioritization in the distribution of vaccines for ethical and optimal result.

Considering these metrics in relation to many of the nations in Africa, the author took note of the additional social burdens that will weigh on the allocation of vaccines, amongst which are ethnic identity issues, urban versus rural dichotomy, rich against poor, family of government leaders versus everyone else, and other conflation of challenges dictated by the unique attributes of African communities and politics. Historically, distribution of national projects and national largesse have been done on tribal lines. Therefore, the author assumed that ethnocentric considerations would, more likely than not, influence the distribution of vaccines in the respective African nations and the rollout of COVID-19 vaccination programs in these nations.

\section{CONCLUSION}

Soon, we may be talking about Vaccine Tribalism if we leave this matter in the hands of the politicians alone in Africa. In Africa, more likely than wealth, identity politics, cronyism, tribalism, big-man-ism, power, being male, are all factors that may influence vaccine allocation, access, and distribution. The author concludes that, perhaps, the respective nations, under the auspices of the WHO, set up a national task force made up of ethicists, sociologist, and others to design the template for vaccine distribution. The centers for vaccination, should consider basic human comforts, ventilation, and sanitary amenities.

\section{REFERENCES}

[1] Akazili, J., Adjuik, M., Chatio, S., Kanyomse, E., Hodgson, A., Aikins, M., and Gyapong, J. What are the Technical and Allocative Efficiencies of Public Health Centres in Ghana? Ghana Med J 42(4):149-155, 2008

[2] Kyle Ferguson, K., and Caplan, A. Love thy Neighbor? Allocating vaccine in a world of competing obligations, 2020.

[3] Abbas, Muhammed Zaheer. 2020. Practical Implications of "vaccine nationalism': A short-sighted and risky approach in reponse to Covid19. https://www.southcentre.int/research-paper-124-november-2020, https://eprints.qut.edu.au/206694/ Queensland University of Technology, Brisbane, Australia, pgs. 1-20, 2020.

[4] AstraZeneca, "AstraZeneca takes next steps towards broad equitable access to Oxford University's potential Covid-19 vaccine," press release 4 June 2020; https://bit.ly/31vqeRP.

[5] Emanuel, E. J., Persad, C., Kern, A., Buchanan, A., Fabre, C., Halliday, D., et al. An Ethical Framework for Global Vaccine Allocation. Science, 369, (6509), 1309 - 1312. DOI: 10.1126/science.abe2803, http://www.sciencemag.org/help/reprints-and-permissions . September 11, pgs. $1309-1312,2020$.

[6] W.H.O. "More than 150 countries engaged in Covid-19 vaccine global access facility," press release. 15 July 2020. https://bit.ly/34AE2MZ.

[7] Kruger, J., and Dunning, D. Unskilled and Unaware of it: How Difficulties in Recognizing One's Own Incompetence Lead to Inflated Self-Assessments. Journal of Personality and Social Psychology 77(6):1121-1134. DOI: 10.1037//0022-3514.77.6.1121, 1999.

[8] WHO, COVID: WHO says 20 percent of Africans to be vaccinated by end of year. Africanews and AFP, 29/1/2021, press release, https://www.africanews.com

Dr. Ishmael D. Norman is the President and CEO of the Institute for Security, Disaster and Emergency Studies. He was the Director for West Africa and Co-PI for the USAID sponsored Resilient Innovation Lab (RiLab/Higher Education Solutions Network) housed at the University of Health and Allied Sciences, Ho, Volta Region, Ghana. The project was in collaboration with the Center for Strategic and International Studies, 
European Journal of Medical and Health Sciences www.ejmed.org

Stanford University, Disaster Resilient Leadership Academy, Tulane University. The School of Public Health, Makerere University was the Prime. Ishmael was also the PI and Director for West Africa in the Strengthen Leadership for Disaster Resilience Program with DRLA, Tulane University. Dr. Norman was the Head of Department at the Department of Biological, Environmental and Occupational Health Sciences at the School of Public Health, University of Ghana from 2010 through March 2013, where he taught public health legislation, occupational and environmental health sciences and public health ethics. Dr. Ishmael D. Norman holds a PH. D in Public Health from the University of Ghana and Juris Doctor degree from the University of New Hampshire's Franklin Pierce Law Center. 